\title{
Cytostatic activity in the hydrophilic fraction of the crude extract from the White Sea sponge Halichondria panicea
}

\section{Vyacheslav Khalaman', Natalia Chalisova², Konstantin Krasnov ${ }^{3}$, and Marina Alexandrova ${ }^{3}$}

${ }^{1}$ White Sea Biological Station, Zoological Institute, Russian Academy of Sciences, Universitetskaya nab., 1, 199034, Saint Petersburg, Russian Federation

${ }^{2}$ Pavlov Institute of Physiology, Russian Academy of Sciences,

Makarova nab., 6, 199034, Saint Petersburg, Russian Federation

Institute of Toxicology, Federal Medical-Biological Agency,

Bekhtereva Street, 1, 192019, Saint Petersburg, Russian Federation

Address correspondence and requests for materials to Vyacheslav Khalaman, VKhalaman@gmail.com

\begin{abstract}
Halichondria panicea, commonly known as the breadcrumb sponge, is an ecologically aggressive and widespread species in the coastal waters of North Atlantic and North Pacific. Cytostatic activity of the water-soluble extract fraction from the White Sea sponge Halichondria panicea was tested using organotypic cultures of rat liver fragments. The study shows a pronounced negative dosedependent effect of the extract on the development of tissue explants of the test animals. Our results confirm toxicity of the White Sea Halichondria panicea, which was revealed earlier toward marine epibenthic organisms. The chemical nature of a substance or substances responsible for toxic effect is discussed.
\end{abstract}

Keywords: Halichondria panicea, White Sea, organotypic culture, cytostatic activity, crude extract.

Citation: Khalaman, V., Chalisova, N., Krasnov, K., and Alexandrova, M. 2019. Cytostatic activity in the hydrophilic fraction of the crude extract from the White Sea sponge Halichondria panicea. Bio. Comm. 64(1): 41-45. https://doi.org/10.21638/ spbu03.2019.105

Author's information: Vyacheslav Khalaman, Dr. of Sci. in Biology, Leading Researcher, orcid.org/0000-0001-5426-0607, Natalia Chalisova, Dr. of Sci. in Biology, Leading Researcher, orcid.org/0000-00022371-0043; Konstantin Krasnov, PhD Leading Researcher, orcid.org/0000-00031503-2243; Marina Alexandrova, PhD, Head of the Laboratory, orcid.org/0000-00019118-7947

Manuscript Editor: Thomas CG Bosch, Institute of Zoology, Christian-AlbrechtsUniversitat zu Kiel, Kiel, Germany

Received: November 22, 2018;

Revised: April 1, 2019;

Accepted: April 9, 2019;

Copyright: ( 2019 Khalaman et al. This is an open-access article distributed under the terms of the License Agreement with Saint Petersburg State University, which permits to the authors unrestricted distribution, and self-archiving free of charge.

Funding: This work was supported by the Program of Division of Biological Sciences RAS (Reg. number AAAA-A19-119022690122-5).

\section{Introduction}

Halichondria panicea (Pallas, 1766), commonly known as the breadcrumb sponge, is a widespread species in the coastal waters of the North Atlantic, Mediterranean Sea and North Pacific (Erpenbeck et al., 2004) and is also known from the Indian Ocean (Purushottama et al., 2009). The substances exuded into seawater by $H$.panicea and the extracts obtained from this sponge were shown to have high biological activity. The excretory-secretory products (ESPs) of H.panicea exhibit a larvicidal effect (Dyrynda, 1983) and the extracts from this sponge are toxic for human and chicken erythrocytes (Purushottama et al., 2009) and for cell cultures of mouse lymphoma (Althoff, 1998). The extracts from H.panicea also have antimicrobial effects (Thompson et al., 1985) and the proteins isolated from these extracts were shown to act as neuromodulators (Purushottama et al., 2009). Some products of the Streptomyces strain HB202, which were isolated from the sponge H.panicea from the Baltic Sea, exhibit antibacterial activity against several pathogenic bacteria and cytotoxic activity against eight human cancer cell lines. These products have been identified as streptophenazines and mayamycin (Schneemann et al., 2010; Kunz et al., 2014).

The concentration of toxic substances in sponges of the same species is known to vary with season and geographic region (Althoff, 1998; Page et al., 2005). The colonies of $H$. panicea living at the margin of the distribution range of this species, in the subarctic regions, for instance, off the shores of Alaska (Knowlton and Highsmith, 2005) or in the White Sea (Gerasimova and Ereskovsky, 2007; Khalaman and Komendantov, 2011), remain largely unexplored in this respect. Never- 
theless, a few existing studies on the subject suggest that the sponges living in polar and subpolar regions can be a promising source of both new and known biologically active substances, to an extent comparable with those sponges that inhabit temperate and tropical seas (Abbas et al., 2011).

Our previous studies have demonstrated that the substances exuded into seawater by $H$.panicea living in the White Sea induce settlement but inhibit larval metamorphosis in the bivalve Mytilus edulis L. (Khalaman et al., 2009) and the ascidian Styela rustica L. (Khalaman et al., 2008), which eventually results in the death of the larvae. The ESPs of the sponge were also lethal to the larvae of conspecifics (Khalaman et al., 2014). Despite some evidence of toxic effects of the substances produced by the White Sea sponge $H$. panicea, the cytotoxic character of these effects remains hypothetical. Because a cytotoxic impact of extracts from $H$.panicea inhabiting the Adriatic, the Arabian, the Baltic and the North Seas was revealed (Althoff, 1998; Purushottama et al., 2009), a cytotoxic activity of the extract from the White Sea sponge was expected. However, it must be verified. For this reason, the aim of the present study was to test the hypothesis that the extracts from $\mathrm{H}$. panicea living in the White Sea have a cytotoxic or cytostatic effect on the tissues of vertebrate animals.

\section{Material and Methods}

\subsection{SAMPLING}

The sponge Halichondria panicea was sampled in June 2017 from the fouling on nylon ropes placed at a depth of 1-3 $\mathrm{m}$ in Krivozerskaya Bay located near the White Sea Biological Station of the Zoological Institute, Russian Academy of Sciences ( $6^{\circ} 20.24^{\prime}$, E 33 38.21') (Kandalaksha Bay of the White Sea).

\subsection{PREPARATION AND FRACTIONATION OF EXTRACTS}

Freshly collected specimens of $H$.panicea were rinsed with sea water and then with fresh water in order to remove dirt and sea salt. During rinsing, all associated macroorganisms and detritus were carefully removed. The sponge was then slightly squeezed and sliced into fragments of about $1 \mathrm{~cm}^{3}$ to obtain crude material with $83 \%$ moisture content. Eight hundred g of wet weight of the sliced sponge was placed in a glass $2.5 \mathrm{~L}$ container, $1.2 \mathrm{~L}(40 \%$ / $60 \%)$ of acetone-methanol mixture was added and the container was left for 5 days at $25^{\circ} \mathrm{C}$. The extract was filtered through a coarse cotton-wool filter to produce $950 \mathrm{~mL}$ of clear light-yellow solution. This filtrate was concentrated to a volume of $100 \mathrm{~mL}$ on a rotary evaporator at a temperature not higher than $70^{\circ} \mathrm{C}$. The concentrate was extracted 3 times with $30 \mathrm{~mL}$ of dichloromethane. The dichloromethane phases were dis- carded and the aqueous solution was evaporated on a rotary evaporator under reduced pressure at a temperature not higher than $70^{\circ} \mathrm{C}$ until a resinoid substance was obtained. This product was held for $4 \mathrm{~h}$ at the final pressure of $1 \mathrm{mBar}$ until water and residual solvents were completely removed. The resulting brown, pungent-smelling amorphous product (18.7 g) was transferred to an airtight glass vial and was stored at room temperature. The output of the product by weight was $2.3 \%$ of the original wet material or $13.7 \%$ of the dry sponge. When a small aliquot of product was dissolved in water, it produced a light yellow solution with weak opalescence.

\subsection{CYTOSTATIC ASSAY}

The assay of the cytostatic effect produced by the H.panacea extract was performed using organotypic cultures of tissue fragments (Freshney, 1994; Chalisova and Zhekalov, 2015). The liver of adult male Wistar rats with a body weight of 250-300 g was chosen as a test tissue. All procedures were carried out under local institutional guidelines (Pavlov Institute of Physiology RAS Animal Welfare and Ethical Review Board). The study was conducted in five methodologically equivalent experiments started on 17, 19, 23, 25 and 27 July 2017. Each experiment used a liver from a different individual (total $\mathrm{n}=5$ ).

The following design was used in each individual experiment. Rat liver was dissected out in sterile conditions and was divided into fragments of about $1 \mathrm{~mm}^{3}$. Each fragment was placed in a separate Petri dish coated with polylysine. The control dishes were incubated with $3 \mathrm{~mL}$ of culture medium. The culture medium consisted of $35 \%$ Eagle medium, 35\% Hank's solution, and 25\% fetal calf serum. The medium was supplemented with glucose $(0.6 \%)$ and gentamicin $(100 \mathrm{U} / \mathrm{mL})$. Test dishes were incubated with the same volume of a similar cultivation medium containing the sponge extract at concentrations of $0.5,1.0,1.5$ or $2.0 \mathrm{mg}$ per $\mathrm{mL}$ of the medium. For each of the four concentrations and controls, six replicates were used.

Explants were incubated in Petri dishes for 3 days at $37^{\circ} \mathrm{C}$ under $5 \% \mathrm{CO}_{2}$. During the incubation, the explants flattened out (rat liver tissue fragments) and the proliferative and migrating cells constituting the growth zone expanded from the margin of the explant. The peripheral growth zone and the central area occupied by the initial transplant were visually different and readily identifiable under a phase-contrast microscope. After the period of exposure, tissues were assessed for their relative growth $(\mathrm{RG})$ using the following formula:

$$
\mathrm{RG}=(\mathrm{SF}-\mathrm{SI}) / \mathrm{SI},
$$

where SI is the initial area of the explant corresponding to its central zone and SF is the final area of the 
explant corresponding to the sum of the areas of the central and growth zones. The explants were visualized using a microtele-attachment for the microscope (series 10, MTN-13) produced by Al'fa_Telekom (Russia). The analysis of the images was performed using free software PhotoM 1.2 (http://www.t_lambda.chat.ru) (Russia).

\subsection{STATISTICAL ANALYSIS}

The effects of the hydrophilic fraction of crude extract and experimental series on the relative growth (RG) of liver tissue (dependent variables) were tested using twoway ANOVA. The concentration of the sponge extract in the cultivation medium and serial number of experiment were selected as categorical factors. Data were first evaluated to ensure that the assumptions for ANOVA were met. Cochran's $C$ test was used to check homogeneity of variance. Normality of distribution was tested using the Kolmogorov-Smirnov test. Comparisons of the means were made using post-hoc LSD test. Significance level was set at $P=0.05$. Mean values were given with their standard errors. Data were processed using STATISTICA $^{\mathrm{TM}}$ software (StatSoft) Release 7.

\section{Results}

The H. panicea extract has a clear negative dose-dependent effect on rat liver explants (Fig. 1). When the extract concentration in the culture solution is $2 \mathrm{mg} / \mathrm{mL}$, the growth zone on the explants is almost absent, which may indicate that under this level of exposure there is no cell proliferation in the tissue and/or cell emigration. ANOVA tests confirm a highly significant effect of the concentration of the sponge extract on the development of explants (Table 1). The differences between the experiments conducted on different days were also statistically significant (Table 1), suggesting variation in individual rat physiological characteristics. In the controls, differences between relative growth values (RG, see formula in section 3.3) for the tissues taken from different animals were as high as 1.5 -fold. For instance, RG values were $1.6 \pm 0.054$ and $1.02 \pm 0.032(P=0.0004)$ for the rats used on 17 and 19 July 2017, respectively. However, at an extract concentration of $2 \mathrm{mg} / \mathrm{mL}$ this parameter showed no significant difference between experiments and, therefore, between the specimens $(P>0.77)$. In all experiments, despite different initial activity of tissues,

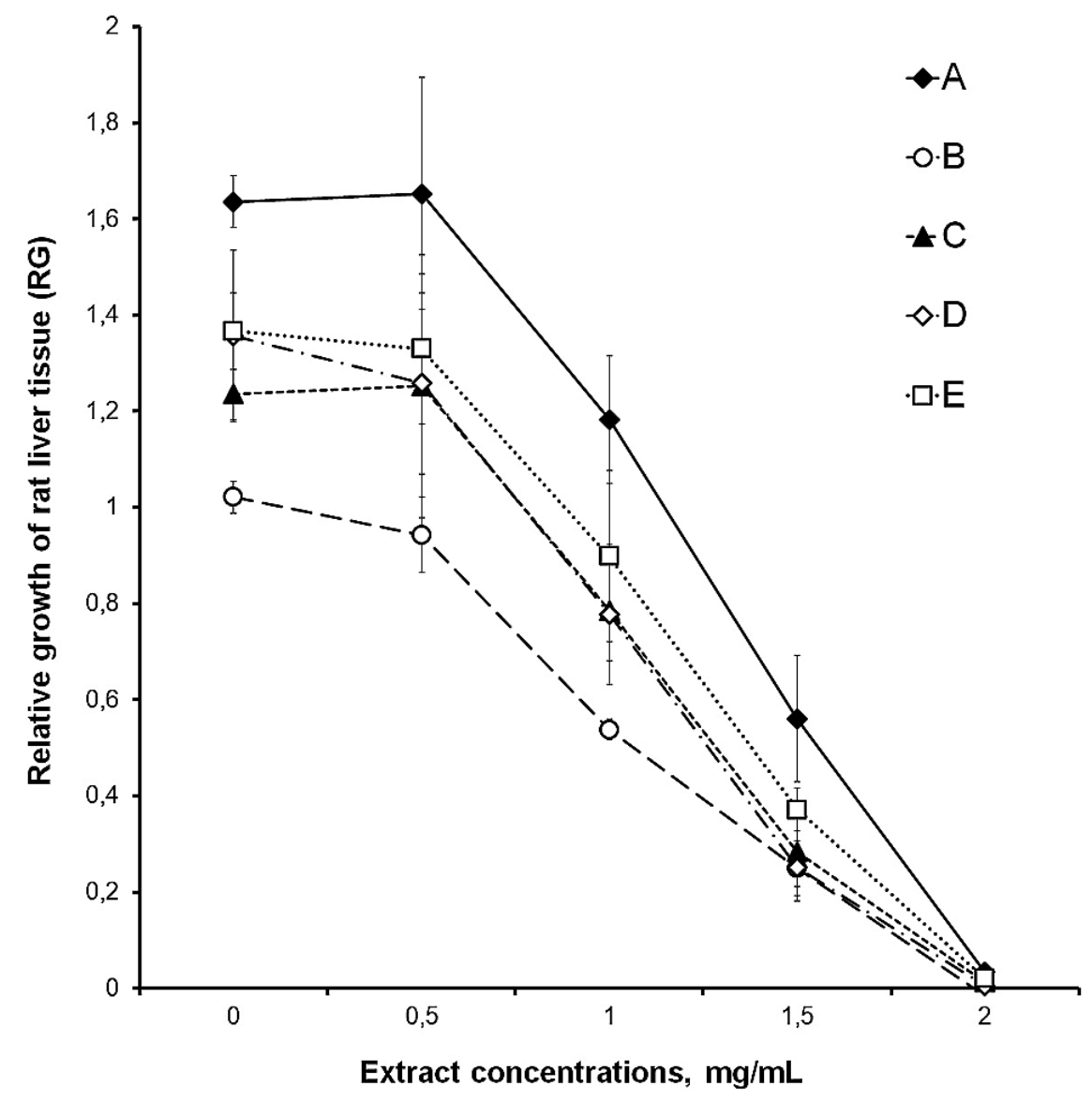

Fig. 1. Relative growth (RG) of tissue explants of the rat liver as a function of the concentration of the $H$. panicea extract in the cultivation medium. A - Results of the experiment started on 17.07.2017 (Rat 1); B - 19.07.2017 (Rat 2); C - 23.07.2017 (Rat 3); D - 25.07.2017 (Rat 4); E - 27.07.2017 (Rat 5). 
Table 1. Results of ANOVA on factors affecting relative growth of rat liver tissue

\begin{tabular}{l|c|c|c|c|c}
\hline \multicolumn{1}{c|}{ Factor } & SS & DF & MS & F & p \\
\hline Concentration & 40.066 & 4 & 10.01 & 115.7 & $<0.0001$ \\
\hline Number of experiment & 3.41 & 4 & 0.85 & 9.86 & $<0.0001$ \\
\hline Conc. * N. of exp. & 1.06 & 16 & 0.066 & 0.76 & 0.72 \\
\hline Residual & 10.82 & 125 & 0.087 & & \\
\hline
\end{tabular}

the development of explants was equally suppressed by the sponge extract. This is confirmed by the lack of interaction between factors 'Concentration' and 'Number of experiment' (Table 1).

\section{Discussion}

The chemical nature of the substance or substances responsible for this effect is as yet unknown. This mixture could contain both the substances already extracted from the specimens of $H$. panicea living in the other regions of the world ocean, such as paniceins (Cimino, 1973), streptophenazines (Kunz et al., 2014), mayamycin (Schneemann et al., 2010) and several others (Indraningrat et al., 2016), and as yet unknown substances. It is of interest that the effect of ESPs of the White Sea H.panicea on the larvae of the ascidian Styela rustica (Khalaman et al., 2008) is similar to that exerted by haliclonacyclamine A, a cytotoxic alkaloid extracted from the sponge Haliclona sp., on the larvae of the ascidian Herdmania curvata (Green et al., 2002). In both cases, larval settlement is induced, but further development of the larvae is stopped to the extent that tissues may undergo necrosis.

It should be noted that the cytostatic activity of the extract from the White Sea $H$. panicea is comparable, for instance, to extracts from the leaves of the tropical plant of the genus Hyptis, which are widely used in traditional medicine and are currently under active study (Ximenes et al., 2013; Cui et al., 2017). Thus, the results of this study indicate that the water-soluble fraction of the extract from the White Sea sponge $H$. panicea has at least a cytostatic effect on live tissues, which may be of interest for development of new anti-cancer drugs.

\section{References}

Abbas, S., Kelly, M., Bowling, J., Sims, J., Waters, A., and Hamann, M. 2011. Advancement into the Arctic region for bioactive sponge secondary metabolites. Marine Drugs 9:2423-2437. https://doi.org/10.3390/md9112423

Althoff, K., Schutt, C., Steffen, R., Batel, R., and Muller, W. E. G. 1998. Evidence for a symbiosis between bacteria of the genus Rhodobacter and the marine sponge Halichondria panicea: Harbor also for putatively toxic bacteria? Marine Biology 130:529-536. https://doi.org/10.1007/ s002270050273

Chalisova, N. I. and Zhekalov, A. N. 2015. The effect of dipeptides consisting of leucine and lysine on cell proliferation in an organotypic culture of myocardium and spleen tissue from young and old rats. Advances in Gerontology 5(3):18083. https://doi.org/10.1134/S2079057015030042

Cimino, G., De Stefano, S., and Minale, L. 1973. Paniceins, unusual aromatic sesquiterpenoids linked to a quinol or quinon system from the marine sponge Halichondria panicea. Tetrahedron 29:2565-2570. https://doi. org/10.1016/0040-4020(73)80174-7

Cui, H.X., Tang, L., Cheng, F. R., and Yuan, K. 2017. Antitumor effects of ethanol extracts from Hyptis rhomboidea in H22 tumor-bearing mice. Pharmacognosy Magazine 13(52):571-575. https://doi.org/10.4103/pm.pm_314_16

Dyrynda, P.E.J. 1983. Modular sessile invertebrates contain larvatoxic allelochemicals. Developmental and Comparative Immunology 7:621-624. https://doi. org/10.1016/0145-305X(83)90078-2

Erpenbeck, D., Knowlton, A. L., Talbot, S. L., Highsmith, R. C., and van Soest, R. W. M. 2004. A molecular comparison of Alaskan and North East Atlantic Halichondria panicea (Pallas 1766) (Porifera: Demospongiae) populations. Bollettino dei Musei e Degli Istituti Biologici dell'Università di Genova 68:319-325.

Freshney, R. I. 1994. Culture of animal cells: a manual of basic technique. 3rd edition. New York: Wiley-Liss.

Gerasimova, E.I. and Ereskovsky, A. V. 2007. Reproduction of two species of Halichondria (Demospongiae: Halichondriidae) in the White Sea. In: Custódio MR, LôboHajdu G., Hajdu E., Muricy G., (eds.) Porifera research biodiversity: innovation and sustainability. Série Livros 28. Rio de Janeiro: Museu Nacional; 327-333.

Green, K. M., Russell, B.D., Clark, R.J., Jones, M. K., Garson, M. J., Skilleter, G. A., and Degnan, B. M. 2002. A sponge allelochemical induces ascidian settlement but inhibits metamorphosis. Marine Biology 140:355-363. https://doi.org/10.1007/s002270100698

Indraningrat, A. A. G., Smidt, H., and Sipkema, D. 2016. Bioprospecting sponge-associated microbes for antimicrobial compounds. Marine Drugs 14(5):87. https://doi. org/10.3390/md14050087

Khalaman, V.V., Belyaeva, D. V., and Flyachinskaya, L. P. 2008. Effect of excretory-secretory products of some fouling organisms on settling and metamorphosis of the larvae of Styela rustica (Ascidiae). Russian Journal of Marine Biology 34(3):170-173. https://doi.org/10.1134/ S106307400803005X

Khalaman, V.V., Flyachinskaya, L. P., and Lezin P. A. 2009. Impact of excretory-secretory products of some fouling organisms on settling of mussel's larvae (Mytilus edulis L. Bivalvia, Mollusca). Invertebrate Zoology 61(1):65-72. https://doi.org/10.15298/invertzool.06.1.06

Khalaman, V. V. and Komendantov, A. Yu. 2011. Structure of fouling communities formed by Halichondria panicea (Porifera: Demospongiae) in the White Sea. Russian Journal of Ecology 42(6):493-501. https://doi.org/10.1134/ S1067413611050080

Khalaman, V. V., Korchagina, N. M., and Komendantov, A. Yu. 2014. The impact of waterborne cues from conspecifics and other species on the larvae of Halichondria panacea Pallas, 1766 (Porifera: Demospongiae). Russian Journal of Marine Biology 40(1):36-42. https://doi.org/10.1134/ S1063074014010064

Knowlton, A. S. and Highsmith, R. C. 2005. Nudibranch-sponge feeding dynamics: Benefits of symbiont-containing sponge to Archidoris montereyensis (Cooper, 1862) and recovery of nudibranch feeding scars by Halichondria panicea (Pallas, 1766). Journal of Experimental Marine Biology and Ecology 327:36-46. https://doi.org/10.1016/j. jembe.2005.06.001 
Kunz, A. L., Labes, A., Wiese, J., Bruhn, T., Bringmann, G., and Imhoff, J. F. 2014. Nature's lab for derivatization: New and revised structures of a variety of streptophenazines produced by a sponge-derived Streptomyces strain. Marine Drugs 12:1699-1714. https://doi. org/10.3390\%2Fmd12041699

Page, M., Northcote, P., Battershill, C., and Kelly, M. 2005. Spatial and temporal variability of cytotoxic metabolites in populations of the New Zealand sponge Mycale hentscheli. Journal of Chemical Ecology 31(5):1161-1174. https://doi.org/10.1007/s10886-005-4254-0

Purushottama, G. B., Venkateshvaran, K., Pani Prasad, K., and Nalini, P. 2009. Bioactivities of extracts from the marine sponge Halichondria panicea. Journal of Venomous Animals and Toxins Including Tropical Diseases 15(3):444-459. https://doi.org/10.1590/S1678-91992009000300007
Schneemann, I., Kajahn, I., Ohlendorf, B., Zinecker, H., Erhard, A., Nagel, K., Wiese, J., and Imhoff, J. F. 2010. Mayamycin, a cytotoxic polyketide from a Streptomyces strain isolated from the marine sponge Halichondria panicea. Journal of Natural Products 73:1309-1312. https://doi. org/10.1021/np100135b

Thompson, J. E., Walker, R. P., and Faulkner, D. J. 1985. Screening and bioassays for biologically-active substances from $40 \mathrm{ma}$ rine sponge species from San Diego, California, USA. Marine Biology 88:11-21. https://doi.org/10.1007/BF00393038

Ximenes, R. M., Melo, A. M., Magalhães, L. P. M., de Souza, I. A. and de Albuquerque, J. F. C. 2013. Antitumor activity of leaves from Hyptis mutabilis (A. Rich.) Briq. (Lamiaceae) in mice bearing tumor. Dataset Papers in Pharmacology. Volume 2013, Article ID 169357, 3 pages. https://doi. org/10.7167/2013/169357 